\title{
Pemodelan Gerak Parabola yang Dipengaruhi Seretan serta Spin Efek Magnus Bola dengan Program Modellus dan Excell
}

\author{
Purwadi $^{1)}$ dan Ishafit ${ }^{2)}$ \\ ${ }^{1)}$ Program Magister Pendidikan Fisika, Universitas Ahmad Dahlan, \\ Kampus II, J1. Pramuka 42 Yogyakarta 55I6I Indonesia \\ Surat-e: maninblueadi@yahoo.co.id \\ 2)Program Studi Pendidikan Fisika, Universitas Ahmad Dahlan, \\ Kampus III, J1. Prof. Dr. Soepomo, SH, Yogyakarta 55164 Indonesia \\ Surat-e: hafit_uad@yahoo.com
}

Gerak parabola adalah gerak yang banyak dijadikan sebagai model untuk pengajaran Fisika khususnya kinematika dalam hal penjumlahan kecepatan; dalam hal ini gerak lurus beraturan (GLB) dalam arah horisontal dan gerak lurus berubah beraturan (GLBB) dalam arah vertikal. Dalam kenyataannya, gerak parabola dipengaruhi oleh variabel lain yaitu adanya hambatan udara yang membuat trayektori lintasan tidak lagi berbentuk parabola dengan asumsi adanya gesekan udara. Tendangan Bola dengan melibatkan faktor spin akan membuat lintasan lateral berbentuk melengkung karena adanya Efek Magnus. Dengan menganalisa faktor-faktor yang berpengaruh dalam gerakan benda dan dibantu dengan software Modellus dan Excell, maka dibuat pemodelan untuk gerak benda.

Kata kunci: gerak parabola, gaya seretan, efek Magnus

\section{Pendahuluan}

Gerak parabola adalah topik yang dipakai dalam pengajaran kinematika yang merupakan penggabungan antara gerak arah sumbu $\mathrm{x}$ dan sumbu $\mathrm{y}$. Asumsi yang banyak dipakai adalah gesekan udara diabaikan, meskipun kenyataannya gesekan sangat banyak berperan dalam mengurangi energi gerak benda yang akhirnya mengurangi ukuran trayektori proyektil. Perhitungan kinematika perlu dilengkapi lagi dengan dinamika dengan melibatkan massa dan gaya seretan udara (drag).

Adanya spin bola menyebabkan lintasan pada gerakan bola sepak mengalami pembelokan tajam di ujung lintasannya merupakan bentuk dari efek Magnus. Adanya fenomena ini banyak digunakan para pesepakbola untuk mengecoh penjaga gawang. Tendangan yang lurus seakan menjauhi gawang tiba-tiba diujung lintasan melengkung cepat dan masuk ke gawang dan mencetak gol. Tulisan ini membahas tentang pemodelan gerakan bola dengan melibatkan gaya seretan udara dan efek Magnus. Tujuan pemodelan adalah:
I. Memberi gambaran tentang perbedaan gerak parabola dengan seretan dan tanpa seretan.

2. Mengaplikasikan teori tentang gerak parabola dengan menggunakan Modellus untuk simulasi model dan spreadsheet Excell.

3. Meneliti pengaruh spin bola terhadap bentuk lintasan bola sepak

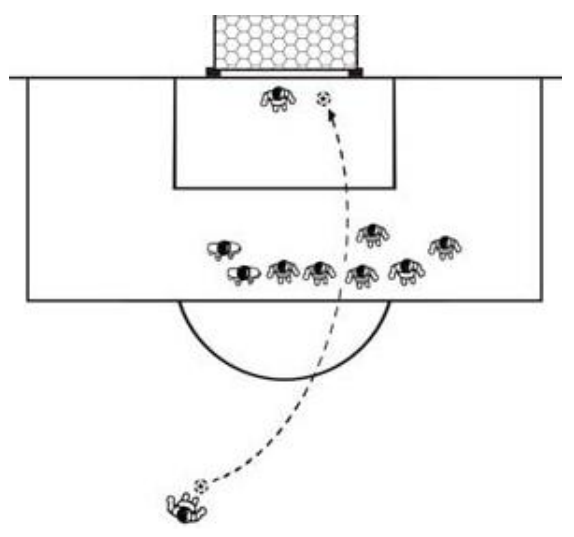

Gambar I. Model pictorial gerakan bola 


\section{Landasan Teori}

Apabila mengabaikan hambatan udara, gaya yang bekerja pada suatu proyektil dengan massa $m$ adalah beratnya yaitu ${ }_{W}=m g$. Komponen dari percepatan proyektil adalah :

$a_{x}=0 \quad a_{y}=-g$

bila sumbu-x adalah arah horisontal dan sumbu-y adalah arah vertikal.

Besaran fisis yang mempengaruhi percepatan gerak bola untuk kasus lintasan pusat massa yaitu massa jenis udara, luas permukaan efektif bola, kecepatan translasional bola, dan koefisien sereta. Selain itu dapat dinyatakan bahwa percepatan bola berbanding terbalik dengan massa bola (http://www.scribd.com/doc/7643894I/Dianto-artikelkolokium-analisis-efek-magnus-pada-lintasan-sepak-bola).

Kita dapat mengestimasi gaya seretan pada sebuah bola. Selain bergantung pada kecepatan, gaya seretan juga bergantung pada kerapatan udara, temperatur dan ketinggian (altitude). Berdasarkan model persamaan gaya hambat, kuantitasnya dipengaruhi oleh Bilangan Reynolds dimana bilangan ini bergantung pada sifat permukaan bola. Bilangan Reynolds didefinisikan sebagai :

$$
R=\frac{\rho v D}{\eta}
$$

Bilangan Reynolds menentukan macam aliran udara yaitu: $R<2000$ bersifat aliran laminer, $R>3000$ bersifat turbulen, $2000<R<3000$ bersifat arus tidak stabil (turbulen dapat timbul dan menghilang). Seretan kritis (critical drag) terjadi ketika aliran laminer pada lapisan batas mulai terpisah dan menjadi turbulen. Energi kinetik hilang di dalam lapisan batas turbulen, pada kondisi ini koefisien drag dapat turun karena rendahnya bilangan Reynolds akibat permukaan bola yang kasar (http://www.scribd.com/doc/7643894I/Dianto-artikelkolokium-analisis-efek-magnus-pada-lintasan-sepak-bola).

Ada dua drag yang terjadi pada bola, yaitu skin friction drag (gaya seretan akibat gesekan antara udara dengan bola) dan pressure drag (gaya seretan akibat aliran ulakan di belakang bola). Pada bola licin, aliran dari depan akan terbelah di sekitar bola, bergerak ke belakang, namun aliran terlepas sebelum sampai di ujung belakang, dan terjadi ulakan-ulakan kecil di belakang bola. Alirannya adalah aliran laminar. Pada bola seperti bola golf yang memiliki dimple/alur, pelepasan aliran ini dapat ditunda, artinya titik pelepasan aliran dapat dapat digeser lebih ke belakang, ulakannya pun lebih sedikit. Aliran pada bola dengan dimple adalah aliran turbulen. Pressure drag pada aliran turbulen lebih kecil daripada aliran laminer. Jadi, dengan memberi lubang kecil pada permukaan bola (menambahkan kekasaran/ roughness) memang akan meningkatkan skin friction drag, tetapi pengurangan/reduksi terhadap pressure drag-nya jauh lebih besar, sehingga drag totalnya lebih kecil (http://www.scribd.com/doc/7643894I/Dianto-artikelkolokium-analisis-efek-magnus-pada-lintasan-sepak-bola).

Pada kecepatan suatu bola tennis dipukul, besar $f$ atau gaya seretan udara

$$
f=\frac{1}{2} \rho v^{2} C_{d} A
$$

yang menyatakan bahwa besarnya gaya berbanding lurus dengan massa jenis udara $\rho$, kecepatan relatif benda terhadap udara $v$, koefisien $\operatorname{drag} C_{d}$ dan luas penampang benda yang terkena udara A (http://www.scribd.com/doc/7643894I/Dianto-artikelkolokium-analisis-efek-magnus-pada-lintasan-sepak-bola). Untuk lebih singkatnya maka :

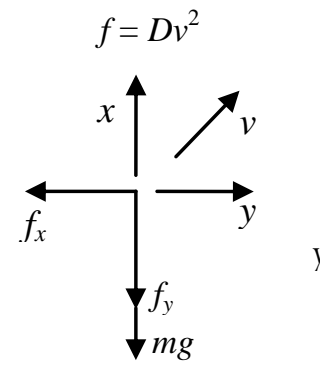

dengan $v=\sqrt{v_{x}^{2}+v_{y}^{2}}$, asumsi bahwa udara diam, sehingga $\vec{v}$ adalah kecepatan proyektil relatif terhadap tanah dan udara, seperti digambarkan di diagram benda bebas berikut:

Gambar 2. Diagram gaya

Arah dari $\vec{f}$ berlawanan dengan arah $\vec{v}$, sehingga bisa dinyatakan sebagai $\vec{f}=-D v \vec{v} \quad$ dan komponen dari $\vec{f}$ adalah :

$$
\begin{gathered}
f_{x}=-D v v_{x} \\
f_{y}=-D v v_{y}
\end{gathered}
$$

Dan tiap komponen adalah berlawanan arah dengan tiap komponen kecepatan sehingga $f=\sqrt{f_{x}^{2}+f_{y}^{2}}$. Dengan hukum II Newton didapatkan :

$$
\begin{gathered}
\sum F_{x}=-D v v_{x}=m a_{x} \\
\sum F_{y}=-m g-D v v_{y}=m a_{y}
\end{gathered}
$$


Komponen dari percepatan termasuk efek dari gravitasi dan drag adalah :

$$
\begin{aligned}
& a_{x}=-(D / m) v v_{x} \\
& a_{y}=-g-(D / m) v v_{y}
\end{aligned} .
$$

Konstanta $D$ bergantung pada kerapatan udara $\rho$, luasan penampang benda A (terlihat dari depan), konstanta tak berdimensi $D$ yang dinyatakan sebagai :

$$
D=\frac{\rho C A}{2}
$$

Ide dasar dari perhitungan numerik adalah komponen percepatan $a_{\mathrm{x}}$ dan $a_{\mathrm{y}}$ selalu berubah dengan komponen kecepatan. Tapi untuk selang waktu yang kecil $\Delta t$, dapat dianggap bahwa percepatan itu konstan. Bila koordinat dan komponen kecepatan pada suatu waktu $t$ diketahui, dapat ditentukan besaran ini pada selang waktu kemudian $t+\Delta t$ untuk percepatan konstan. Selama selang waktu $\Delta t$, komponen percepatan rata-rata adalah $a_{x}=\Delta v_{x} / t$ dan kecepatan-x $v_{x}$ berubah sebesar $\Delta v_{x}=a_{x} \Delta t$. Demikian juga, $v_{y}$ berubah dengan sebesar $\Delta v_{y}=a_{y} \Delta t$.

Nilai dari komponen-x dan komponen y di akhir tiap interval adalah :

$$
v_{x}+\Delta v_{x}=v_{x}+a_{x} \Delta t \quad v_{y}+\Delta v_{y}=v_{y}+a_{y} \Delta t
$$

Apabila ini terjadi maka, proyektil bergerak sehingga koordinat pun berubah. Bila kecepatan rata-rata selama interval waktu $\Delta t$ adalah rata-rata dari nilai $v_{\mathrm{x}}$ (pada awal interval) dan $v_{x}+\Delta v_{x}$ (pada akhir interval) atau $v_{x}+\Delta v_{x} / 2$. Selama $\Delta t$ koordinat $\mathrm{x}$ bertambah sebesar

$$
\Delta x=\left(v_{x}+\Delta v_{x} / 2\right) \Delta t=v_{x} \Delta t+\frac{1}{2} a_{x}(\Delta t)^{2}
$$

Demikian pula untuk $y$. Sehingga koordinat proyektil pada akhir interval adalah :

$$
\begin{aligned}
& x+\Delta x=x+v_{x} \Delta t+\frac{1}{2} a_{x}(\Delta t)^{2} \\
& y+\Delta y=y+v_{y} \Delta t+\frac{1}{2} a_{y}(\Delta t)^{2}
\end{aligned}
$$

Nilai awal $x, y, v_{x}$, dan $v_{y}$ ditentukan dulu, selanjutnya kalkulasi nilai posisi dan kecepatan pada akhir tiap interval sebagai kelipatan dari nilai awalnya, dan akhirnya bisa ditentukan nilai di akhir sejumlah interval (Young dan Freedmann, 2000)

\section{Efek Magnus}

Fenomena tendangan pisang yang banyak mengecoh penjaga gawang adalah contoh dari aplikasi hukum Fisika yang disebut dengan Efek Magnus (Gustav Magnus, I852) (http://www3.wooster.edu/physics/jris/

Files/Ahmad_Web_Article.pdf). Besarnya gaya Magnus dinyatakan sebagai

$$
F_{M}=C_{L} \rho D^{3} f v \hat{F}
$$

Dimana $C_{L}$ adalan koefisien Lift, $D$ adalah diameter bola, $\rho$ adalah massa jenis udara, $f$ adalah frekuensi spin bola dan $v$ adalah kecepatan bola (http://www.scribd.com/doc/7643894I/Dianto-artikelkolokium-analisis-efek-magnus-pada-lintasan-sepak-bola). Untuk mempermudah pemahaman pengaruh spin bola pada arah gaya Magnus maka bisa dilihat pada gambar berikut. Bila spin putar kiri maka tendangan akan melengkung ke kiri dan bila spin putar kanan maka tendangan akan putar kanan.

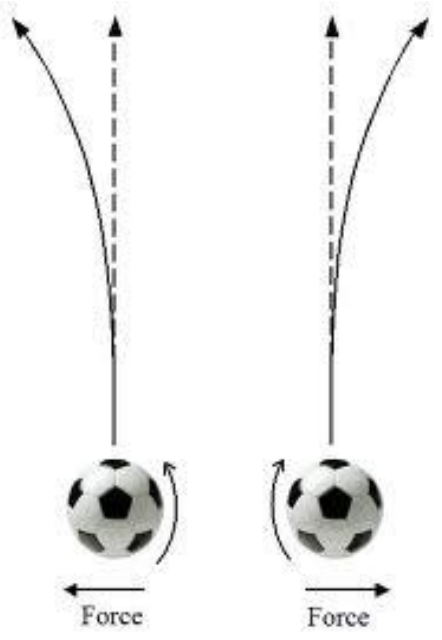

Gambar 3. Gerakan bola akibat spin

Persamaan Bernoulli menyatakan bahwa tekanan statis dan tekanan dinamis yang bekerja pada aliran laminar adalah konstan dinyatakan sebagai berikut : 


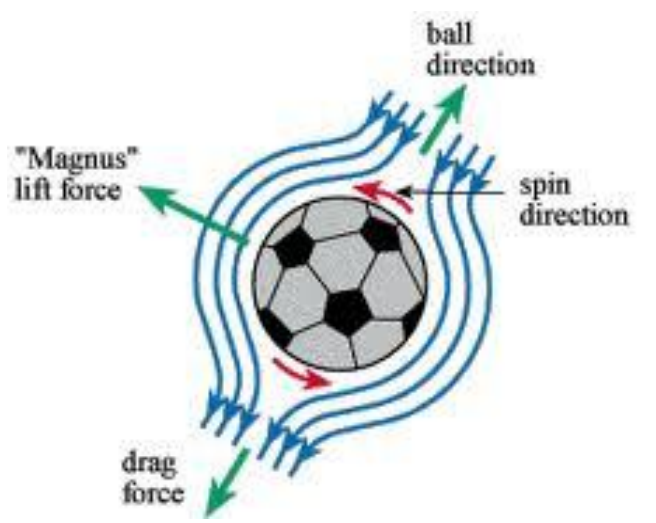

Gambar 4. Aliran laminar

$$
p+\frac{1}{2} \rho v^{2}+\rho g h=k o n s \tan
$$

Dari persamaan Bernoulli, adanya rotasi bola mengakibat kan adanya perbedaan tekanan pada sisi bola yang menghasilkan gaya Magnus.

Karena adanya rotasi bola $\omega$ dengan jari jari $R$ maka kecepatan bola akan menjadi :

$$
\begin{aligned}
& v_{1}=v+\omega R \\
& v_{2}=v-\omega R
\end{aligned}
$$

Bila pers (8) dan (9) dimasukkan ke persamaan Bernoulli maka akan menjadi seperti berikut :

$$
\begin{aligned}
& p_{1}+\frac{1}{2} \rho(v+\omega R)^{2}=p_{2}+\frac{1}{2} \rho(v-\omega R)^{2} \\
& \Delta p=p_{1}-p_{2} \\
& \Delta p=\frac{1}{2} \rho\left[(v+\omega R)^{2}-(v-\omega R)^{2}\right] \\
& \Delta p=2 \rho \omega R v .
\end{aligned}
$$

Besarnya gaya yang bekerja pada kondisi ini :

$$
F=A_{e f f} \cdot \Delta p
$$

Dengan Aeff adalah luas permukaan efektif yang terpapar pada aliran udara sebesar :

$$
A_{\text {eff }}=\pi R^{2}
$$

Jadi besarnya Gaya Magnus adalah :

$$
F=2 \pi \rho \omega R^{3} v
$$

bila dinyatakan secara vektor adalah :

$$
F=2 \pi \rho \omega R^{3} \vec{\omega} \times \vec{v}
$$

\section{Persamaan Gerak Spin Bola Putar Kanan}

Bila dilihat dari samping maka bola bergerak ke arah sumbu $\mathrm{x}^{+}$dan membelok tajam akibat efek magnus sehingga dapat dinyatakan sebagai berikut :(http://www.scribd.com/doc/7643894I/Dianto-artikelkolokium-analisis-efek-magnus-pada-lintasan-sepak-bola)

$$
\begin{aligned}
& \sum_{\vec{F}_{m}} F=m g \hat{j}=m\left(a_{x} \hat{i}+a_{y} \hat{j}\right) \\
& C_{L} \rho D^{3} f\left(-v_{x} \hat{j}+v_{y} \hat{i}\right)-m g \hat{j}=m\left(a_{x} \hat{i}+a_{y} \hat{j}\right)
\end{aligned}
$$

Komponen $\hat{1}$ :

$$
\begin{aligned}
& C_{L} \rho D^{3} f v_{y}=m a_{x} \\
& C_{L} \rho D^{3} f v_{y}=m \frac{d v_{x}}{d t} \\
& C_{L} \rho D^{3} f \frac{d v_{y}}{d t}=m \frac{d^{2} v_{x}}{d t^{2}}
\end{aligned}
$$

Komponen $\hat{\jmath}$ :

$$
\begin{gathered}
-C_{L} \rho D^{3} f v_{x}-m g=m a_{y} \\
-C_{L} \rho D^{3} f v_{x}-m g=m \frac{d v_{y}}{d t} \\
-C_{L} \rho D^{3} f \frac{d v_{x}}{d t}=m \frac{d^{2} v_{y}}{d t^{2}}
\end{gathered}
$$

Bila disubstitusikan persamaan (I3) dan (I6) maka:

$$
\begin{aligned}
& \frac{d v_{x}}{d t}=\frac{C_{L} \rho D^{3} f v_{y}}{m} \\
& -C_{L} \rho D^{3} f v_{y}=\frac{m^{2}}{C_{L} \rho D^{3} f} \frac{d^{2} v_{y}}{d t^{2}} \\
& \frac{d^{2} v_{y}}{d t^{2}}+\left(\frac{C_{L} \rho D^{3} f}{m}\right)^{2} v_{y}=0
\end{aligned}
$$

Bila (I3) disubstitusikan pers. (I4) dan (I5) maka akan dihasilkan persamaan gerak bola sebagai berikut :

$$
\begin{gathered}
\frac{d v_{y}}{d t}=\frac{m}{C_{L} \rho D^{3} f} \frac{d^{2} v_{x}}{d t^{2}} \\
-C_{L} \rho D^{3} f v_{x}-m g=\frac{m^{2}}{C_{L} \rho D^{3} f} \frac{d v_{y}}{d t} \\
\frac{d^{2} v_{x}}{d t^{2}}+\left(\frac{C_{L} \rho D^{3} f}{m}\right)^{2} v_{x}=-\frac{g}{m}
\end{gathered}
$$

Solusinya adalah : 


$$
\begin{aligned}
& v_{y}(t)=-A \sin (\omega t)+v_{o} \sin (\theta) \cos (\omega t) \\
& v_{x}(t)=-\frac{g}{\omega}+A \cos (\omega t)+v_{o} \sin (\theta) \sin (\omega t)
\end{aligned}
$$

Dengan :

$$
\omega=\frac{C_{L} \rho D^{3} f}{m} \quad \text { dan } A=\frac{\left(g+v_{o} \cos (\theta) \cdot \omega\right)}{\omega}
$$

Diperoleh :

$$
\begin{array}{r}
x=-\frac{g}{\omega} t+\frac{A}{\omega} \sin (\omega t)-\frac{v_{o} \sin \theta}{\omega} \cos (\omega t)+\frac{v_{o} \sin \theta}{\omega} \\
y=\frac{A}{\omega} \cos (\omega t)+\frac{v_{o} \sin \theta}{\omega} \sin (\omega t)-\frac{A}{\omega}
\end{array}
$$

\section{Persamaan Gerak Spin Bola Putar Kiri}

Peristiwa sebaliknya bila bola berotasi berlawanan arah jarum jam atau dari samping bergerak ke sumbu $x$ - apabila dirumuskan sebagai berikut: (http://www.scribd.com/doc/7643894I/Dianto-artikelkolokium-analisis-efek-magnus-pada-lintasan-sepak-bola)

$$
\begin{aligned}
& \sum F=m a \\
& F_{m}-m g \hat{j}=m\left(a_{x} \hat{i}+a_{y} \hat{j}\right) \\
& C_{L} \rho D^{3} f\left(v_{x} \hat{j}-v_{y} \hat{i}\right)-m g \hat{j}=m\left(a_{x} \hat{i}+a_{y} \hat{j}\right)
\end{aligned}
$$

Bila dinyatakan dalam komponen $i$ dan $j$ sebagai berikut : Komponen î:

$$
\begin{array}{r}
-C_{L} \rho D^{3} f v_{y}=m a_{x} \\
-C_{L} \rho D^{3} f v_{y}=m \frac{d v_{x}}{d t} \\
-C_{L} \rho D^{3} f \frac{d v_{y}}{d t}=m \frac{d^{2} v_{x}}{d t^{2}}
\end{array}
$$

Komponen $\hat{\mathrm{j}}$ :

$$
\begin{gathered}
C_{L} \rho D^{3} f v_{x}-m g=m a_{y} \\
C_{L} \rho D^{3} f v_{x}-m g=m \frac{d v_{y}}{d t} \\
C_{L} \rho D^{3} f \frac{d v_{x}}{d t}=m \frac{d^{2} v_{y}}{d t^{2}}
\end{gathered}
$$

Bila disubstitusi pers (26) dan (23) akan menjadi:

$$
\begin{gathered}
\frac{d v_{x}}{d t}=-\frac{C_{L} \rho D^{3} f v_{y}}{m} \\
C_{L} \rho D^{3} f v_{y}=\frac{-m^{2}}{C_{L} \rho D^{3} f} \frac{d^{2} v_{y}}{d t^{2}} \\
\frac{d^{2} v_{y}}{d t^{2}}+\left(\frac{C_{L} \rho D^{3} f}{m}\right)^{2} v_{y}=0
\end{gathered}
$$

Substitusi Pers.(24) dan (25) menjadi :

$$
\begin{gathered}
\frac{d v_{y}}{d t}=\frac{-m}{C_{L} \rho D^{3} f} \frac{d^{2} v_{x}}{d t^{2}} \\
C_{L} \rho D^{3} f v_{x}-m g=\frac{-m}{C_{L} \rho D^{3} f} \frac{d^{2} v_{x}}{d t^{2}} \\
\frac{d^{2} v_{x}}{d t^{2}}+\left(\frac{C_{L} \rho D^{3} f}{m}\right)^{2} v_{x}=\frac{g}{m}
\end{gathered}
$$

Solusinya adalah :

$$
\begin{array}{r}
v_{y}(t)=A \sin (\omega t)+v_{o} \sin (\theta) \cos (\omega t) \\
v_{x}(t)=\frac{g}{\omega}+A \cos (\omega t)+v_{o} \sin (\theta) \sin (\omega t)
\end{array}
$$

Dengan :

$$
\omega=\frac{C_{L} \rho D^{3} f}{m} \quad \text { dan } \quad A=\frac{\left(g+v_{o} \cos (\theta) . \omega\right)}{\omega}
$$

Maka :

$$
\begin{gathered}
x=\frac{g}{\omega} t+\frac{A}{\omega} \sin (\omega t)+\frac{v_{o} \sin \theta}{\omega} \cos (\omega t)-\frac{v_{o} \sin \theta}{\omega} \\
y=-\frac{A}{\omega} \cos (\omega t)+\frac{v_{o} \sin \theta}{\omega} \sin (\omega t)+\frac{A}{\omega}
\end{gathered}
$$

Dengan persamaan ini bisa ditentukan simulasi modelnya.

\section{Metode Simulasi}

I.Disiapkan software Modellus, kemudian dimasukkan variabel dan rumus ke dalam mathematical model.

2. Untuk kasus bola tennis maka nilai radius $r=0,0366$ $\mathrm{m}$ dan massa $m=0,145 \mathrm{~kg}$, sedangkan koefisien hambatan udara $C_{D}=0,5$.

3. Nilai kerapatan udara $\rho=1,2 \mathrm{~kg} / \mathrm{m}^{3}$ untuk kecepatan awal bola bisa dicoba kecepatan awal $v_{o}=63,75 \mathrm{~m} / \mathrm{s}$ dan sudut elevasi $\alpha=45^{\circ}$.

4. Dilakukan hal yang sama dengan Excell dan ditampilkan gambar trayektori parabola tanpa drag dan dengan drag. 
5. Untuk pemodelan efek Magnus dilakukan pada bola sepak dengan data geometri yang ditetapkan FIFA yaitu $m=(0,422 \pm 0,010) \mathrm{kg}$ dan diameter $\mathrm{D}$ $(0,216 \pm 0,004) \mathrm{m}$. Diteliti bagaimana pengaruh spin terhadap lintasan bola sepak.

\section{Pembahasan}

\section{Gerak Parabola dengan Drag}

Untuk membuat simulasi model gerak parabola dengan drag maka dimasukkan persamaan sebagai berikut :

I. $A=\pi r^{2}$ untuk menentukan luas penampang bola. Untuk membuat variasi dalam gerak lintasan maka variabel radius bola $r$ serta kecepatan awal $v_{o}$ dimasukkan dalam level indicator sehingga dalam simulasi model bisa digambarkan perbedaan trayektori tanpa drag serta dengan drag.

2. $D=\frac{\rho C A}{2}$ dengan $C_{D}$ merupakan koefisien drag.

Besarnya $\rho=I, 2 \mathrm{~kg} / \mathrm{m}^{3}[\mathrm{I}]$ adalah kerapatan udara pada permukaan air laut.

3. Besarnya gaya gesekan pada arah sumbu-x ditentukan dengan rumus $f_{x}=-D v v_{x}$ dan pada arah sumbu-y $f_{y}=-D v v_{y}$ sedangkan besarnya resultan gaya gesekan dinyatakan sebagai $f=\sqrt{f_{x}^{2}+f_{y}^{2}}$.

4. Untuk menentukan besarnya percepatan pada arah sumbu-x dan sumbu-y adalah sebagai berikut:

$$
a_{x}=-\left(\frac{D}{m}\right) v v_{x} \quad a_{y}=-g-\left(\frac{D}{m}\right) v v_{y}
$$

5.Untuk menentukan besarnya kecepatan pada arah sumbu$\mathrm{x}$ dan sumbu-y adalah sebagai berikut:

$$
v_{x}=v_{o} \cos \alpha+a_{x} t \quad v_{y}=v_{o} \sin \alpha+a_{y} t
$$

Dan resultan dari komponen kecepatan pada sumbu-x dan sumbu-y adalah sebagai berikut :

$$
v=\sqrt{v_{x}^{2}+v_{y}^{2}}
$$

6. Untuk menentukan posisi bola sebagai fungsi waktu dapat dinyatakan sebagai berikut :

$$
\begin{aligned}
& x=v_{x} t+\frac{1}{2} a_{x} t^{2} \\
& y=v_{y} t+\frac{1}{2} a_{y} t^{2}
\end{aligned}
$$

Didapatkan bentuk trayektori gerak seperti berikut

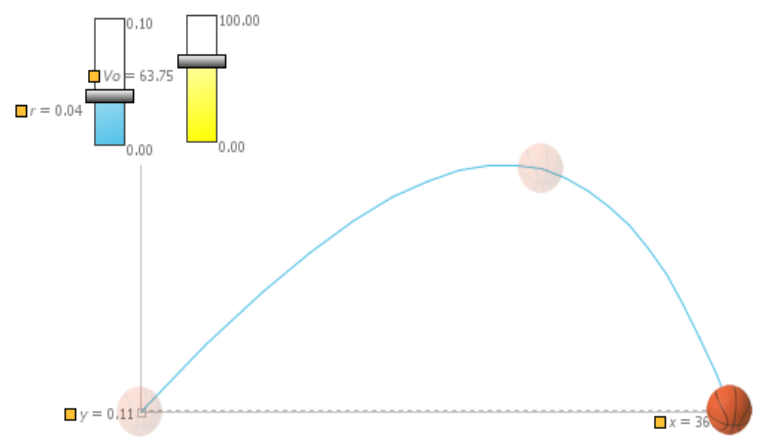

Gambar 5. Kurva Trayektori bola dengan drag untuk jari

$$
\text { jari } r=0,04 \mathrm{~m} \text { dan } v_{o}=63,75 \mathrm{~m} / \mathrm{s}
$$

Dari trayektori terlihat bahwa gerakannya tidak murni parabola lagi tetapi menjadi lebih pendek lintasannya. Untuk menentukan perbandingan jangkauannya, maka dilakukan untuk $r=0$ sehingga dianggap sebagai lintasan titik partikel dan
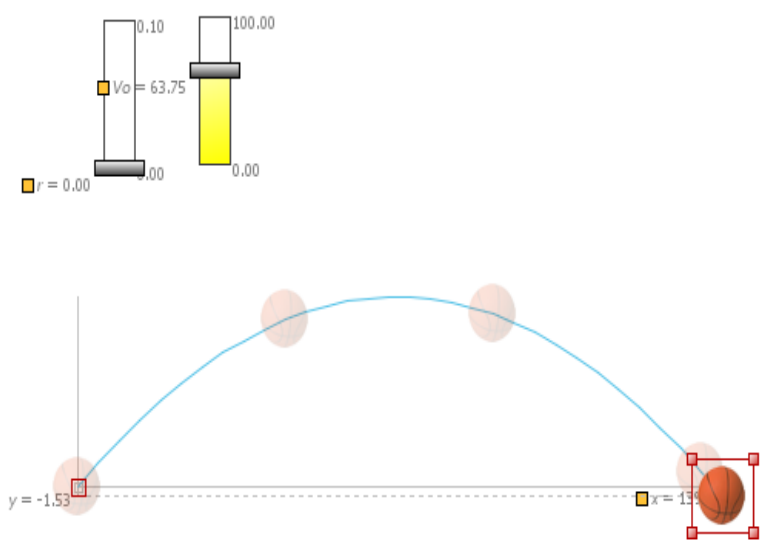

Gambar 6. Kurva Trayektori bola tanpa drag untuk jari jari $r=$ $0,04 \mathrm{~m}$ dan $v_{o}=63,75 \mathrm{~m} / \mathrm{s}$

Untuk membandingkan kedua trayektori tersebut maka bisa juga dilakukan dengan menggunakan Excell. Untuk melakukan simulasi model maka perlu dilakukan setting tersendiri karena adanya perhitungan yang bersifat iteratif (berkaitan). Untuk keperluan itu, maka dari menu file pilih option kemudian pilih formula. Setelah formula ditemukan kemudian diklik enable iterative calculation, maka entry data yang masuk bisa dibuat model. 
Hasil yang didapat dari model simulasinya seperti berikut

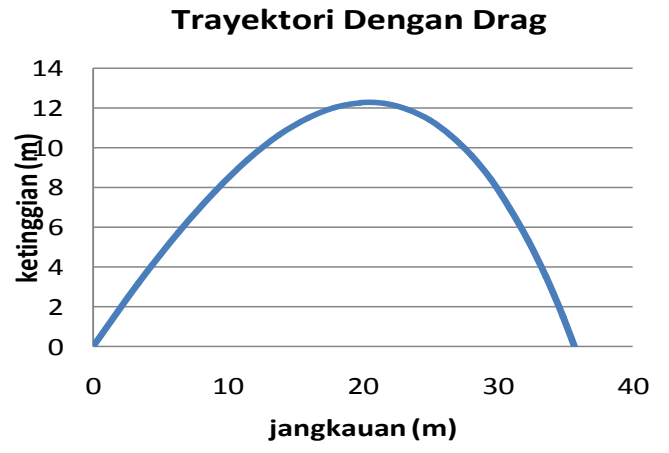

Gambar 7. Trayektori dengan seretan

Trayektori Bola

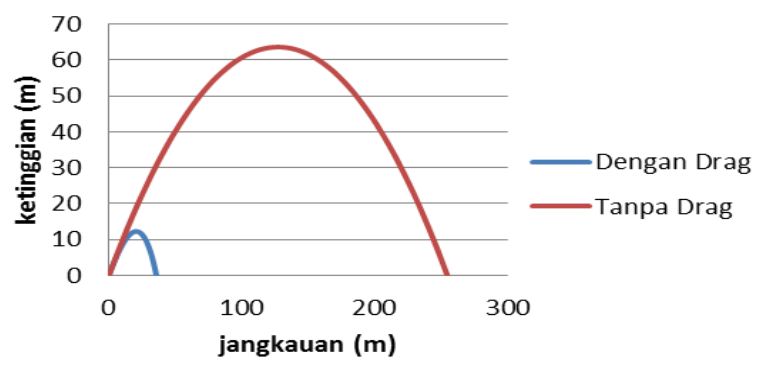

Gambar 8. Trayektori bola

Terlihat dari hasil simulasi bahwa lintasan yang tanpa drag, jarak jangkauannya sekitar 6 kali jangkauan dengan drag. Simulasi ini dilakukan untuk bola dengan $r=0,0366$ $\mathrm{m}$ dan massa $m=0,145 \mathrm{~kg}$ dan kecepatan awal $50 \mathrm{~m} / \mathrm{s}$ dengan sudut elevasi $45^{\circ}$.

\section{Spin Efek Magnus}

Bila tendangan mengenai bola tepat pada pusat massanya maka selama melayang, bola tersebut tidak mengalami rotasi. Sebaliknya, bila bola ditendang tidak tepat pada pusat massanya maka bola akan mengalami spin/rotasi selama gerakannya. Dengan rotasi ini maka akan terjadi efek magnus yang membengkokkan lintasan bola.

Sesuai dengan persamaan gerak untuk $\mathrm{x}$ dan $\mathrm{y}$ untuk putar kanan dan kiri maka didapatkan bentuk simulasi model seperti di bawah ini

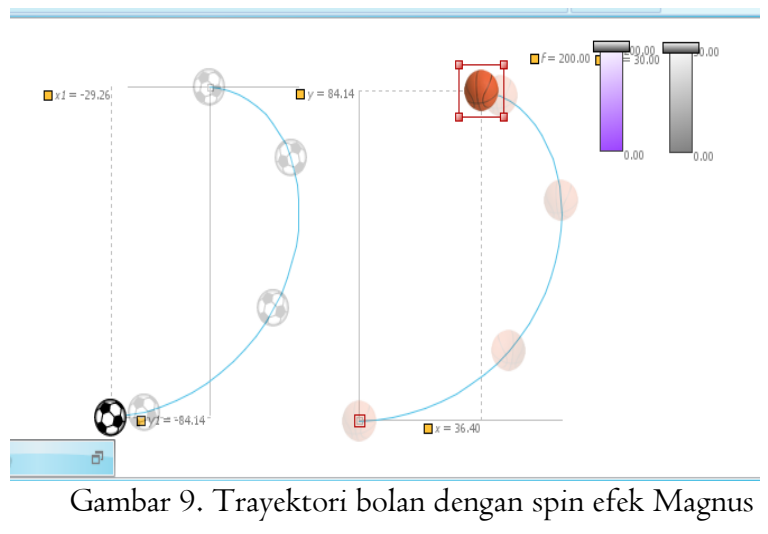

Bila divariasikan nilai dari kecepatan awal bola vo dengan spin bola rendah akan terbentuk lintasan tidak terlalu melengkung tapi cenderung mendekati garis lurus. Tetapi sebaliknya bila frekuensi spin bola $f$ ditingkatkan dengan vo yang rendah maka bola akan melengkung dengan kecepatan linier bola akan berkurang.

Hal ini terjadi karena besarnya energi kinetik translasi bola tereduksi kedalam energi kinetik rotasi. Bila tendangan lurus tanpa spin berarti energi kinetik murni hanya untuk translasi saja, sedangkan pemberian spin bola mengurangi tenaga kinetik bola. Jadi untuk menghasilkan tendangan lengkung yang baik tendangan dilakukan tidak terlalu cepat tapi spin bolanya tinggi. Dari tendangan seperti ini dihasilkan tendangan yang lurus tapi melengkung tajam diujungnya.

Dalam simulasi model ini tentu saja banyak asumsi yang diberikan seperti koefisien lift $C_{L}=1$, tidak adanya angin, kelembaban udara yang rendah dan diabaikannya viskositas udara. Selain hal itu, spin bola juga dianggap konstan dalam simulasi model, meskipun dalam kenyataannya spin makin berkurang ketika mendekati akhir dari lintasan. Faktorfaktor ini tidak diikutkan dalam simulasi untuk mempermudah perhitungan saja.

\section{Kesimpulan}

I. Gerak parabola dengan drag memiliki lintasan yang lebih pendek dibandingkan dengan gerak parabola yang tanpa seretan.

2. Efek Magnus muncul karena adanya spin bola ketika sedang melayang, yang mengakibatkan lintasan bola melengkung.

3. Tendangan lengkung muncul karena energi kinetik translasi bola direduksi ke dalam energi kinetik rotasi yang muncul ketika bola melakukan spin. 


\section{Kepustakaan}

University Physics, Hugh D. Young and Roger Freedmann, New York, Addison Wesley, 2000, p.I46-I47.

http://www.scribd.com/doc/7643894I/Dianto-artikelkolokium-analisis-efek-magnus-pada-lintasan-sepak-bola

http://www3.wooster.edu/physics/jris/

Files/Ahmad_Web_Article.pdf

http://universitasfisika.wordpress.com/kajian-

fenomena/analisis-sepak-bola-fisika/ 